\title{
Affiliation of the J Project Group to the Central European Journal of Immunology
}

\author{
LÁSZLÓ MARÓDI \\ Department of Infectious and Pediatric Immunology, Medical and Health Science Center, University of Debrecen, Debrecen, Hungary
}

(Centr Eur J Immunol 2012; 37 (4): 295-297)

The Editorial Board of the Central European Journal of Immunology (CEJI) has recently approved the affiliation of the J PROJECT Group to the Journal. The CEJI will now provide a new forum for publishing and discussing primary immunodeficiency (PID)-related research in Eastern and Central European (ECE) countries and elsewhere. Now that the J Project has an "official" journal, its professional leaders and members are encouraged to publish not only their original research in the field, but also instructive case reports and registry data, such as those published in this issue $[1,2]$.

\section{Mendelian susceptibility to mycobacterial disease phenotypes and genotypes}

Mendelian susceptibility to mycobacterial disease (MSMD) is now well established as a group of potentially fatal rare congenital disorders/conditions involving a selective predisposition to weakly virulent mycobacteria [3]. Most affected individuals are susceptible to nontuberculous environmental mycobacteria (EM), which are also known as atypical mycobacteria, and to severe clinical disease caused by Bacille Calmette-Guérin (BCG) vaccines, but they are otherwise healthy. They may also present invasive salmonellosis and, less frequently, pulmonary and extrapulmonary infection with Mycobacterium tuberculosis. Other infections are rare. MSMD due to complete interferon (IFN)- $\gamma \mathrm{R} 1$ deficiency was first described by two independent groups in 1996 [4, 5]. Mutations of IFNGR1 may be inherited as autosomal recessive and autosomal dominant traits (Table 1). Mutation affecting the IFN- $\gamma$ signaling receptor chain (IFN- $\gamma$ R2) was first identified in 1998 [6] and, subsequently, four additional recessive, two dominant and one X-linked MSMD gene have been identified

Table 1. Inheritance and genotypes of Mendelian suscetibility to mycobacterial disease (MSMD)

\begin{tabular}{|c|c|c|c|}
\hline Inheritance & Mutated gene & Affected protein & Deficiency \\
\hline Autosomal recessive & IFNGRI & Interferon- $\gamma$ receptor 1 & Complete \\
\hline Autosomal recessive & IFNGRI & Interferon- $\gamma$ receptor 1 & Partial \\
\hline Autosomal recessive & $I F N G R 2$ & Interferon- $\gamma$ receptor 2 & Complete \\
\hline Autosomal recessive & $I F N G R 2$ & Interferon- $\gamma$ receptor 2 & Partial \\
\hline Autosomal recessive & $I L 12 R \beta 1$ & IL-12 receptor $\beta 1$ chain & Complete \\
\hline Autosomal recessive & $I L 12 B$ & IL-12 p40 subunit & Complete \\
\hline Autosomal recessive & $\operatorname{IRF} 8$ & Interferon regulatory factor 8 & Complete \\
\hline Autosomal recessive & $I S G 15$ & $\begin{array}{l}\text { Interferon- } \gamma / \beta \text { inducable, } \\
\text { ubiquitin-like intracellular protein }\end{array}$ & Complete \\
\hline Autosomal dominant & IFNGRI & Interferon- $\gamma \mathrm{R} 1$ & Partial \\
\hline Autosomal dominant & STAT1 & $\begin{array}{l}\text { Signal transducer and } \\
\text { activator of transcription } 1\end{array}$ & Partial \\
\hline Autosomal dominant & $I R F 8$ & Interferon regulatory factor 8 & Partial \\
\hline $\mathrm{X}$-linked recessive & NEMO & $\mathrm{NF}-\kappa \mathrm{B}$ essential modulator & Partial \\
\hline
\end{tabular}


[3, 7-9] (Table 1). These reports highlight the role of the IFN- $\gamma$ - IL-12 circuit in general, and of IFN- $\gamma$, a pleiotropic cytokine, in particular, in controlling invasive infection due to mycobacteria and other intracellular parasites. Human IFN- $\gamma$ appears to activate macrophages more strongly than antiviral IFN. The severity of clinical disease due to mutations of MSMD genes varies between affected individuals and genotypes (Table 1). However, no genetic etiology has yet been defined for about half the patients with MSMD.

Al-Muhsen and Casanova recently surveyed the geographic origins of patients with MSMD and found that cases had been reported in 44 countries, on six different continents [3]. This broad distribution of mutant alleles contrasts with the negligible number of cases diagnosed and reported in ECE countries. Only four patients with autosomal recessive complete IFNGR1 deficiency from Slovakia (three patients) and Poland (one patient), and one patient with autosomal dominant partial IFNGR 1 deficiency from the Czech Republic have been diagnosed genetically (J Bustamante and J-L Casanova, personal communication). The Czech patient with partial IFNGR1 deficiency carried an 818del4/WT mutation similar to that identified in the twoyear-old girl described by M. Pac et al. in this issue [1]. In line with the current national vaccination protocols of Poland and most other ECE countries, this girl was vaccinated with BCG vaccine at birth; she presented with disseminated mycobacterial infection at three months of age. The life of this patient was saved by combination therapy with six (!) antituberculosis agents, but this report argues against the routine use of BCG vaccine in newborns, given the potential risk of invasive disease. There is an even greater risk of disseminated BCG-osis in patients with complete IFNGR1 deficiency and in those with severe combined immunodeficiency disorders (SCID) [10]. Newborn screening for SCID may be introduced in the future, but this would identify only a fraction of the neonates with susceptibility to severe infection in early infancy, and the current financial situation may postpone the introduction of such screening programs in ECE countries for some time. The case report from Pac et al. also highlights the importance of awareness and of the early diagnosis of PIDs, including MSMDs, before the development of generalized disease. In ECE countries, we need more PID centers and the use of advanced technologies for molecular genetic diagnosis and family screening. Existing centers, such as the Children Memorial Health Institute in Warsaw, with its long-standing dedication to PID care, indicate the direction in which we should be heading. The Warsaw team and with the Pediatric Hematology team subsequently established at the Jagiellonian University in Krakow have established themselves as leaders of the field in this region in recent decades. The Warsaw team has also extended its activities to Eastern Europe and has made a major contribution to the success of the J Project, a physician education and research collaboration program established 8 years ago $[11,12]$.

\section{PID registry and non-immune PID phenotypes}

Another PID paper published in this issue, by Pirrone et al., carefully analyzes 136 PID patients diagnosed at two neighboring centers, in North Eastern Italy (Trieste) and Slovenia. These two centers provide long-standing and high professional level PID care for a population of 3.5 million people. In addition to carrying out statistical analyses of the distribution of various PIDs classified as recommended by the IUIS PID expert committee [13], these authors focused on complex clinical phenotypes. Increasing numbers of nonimmune PID phenotypes are being described, suggesting complex clinical manifestations other than infectious complications [14]. Multidisciplinary approaches are therefore required, for the diagnosis of PIDs with non-immune phenotypes and non-immune signs, such as autoimmune polyendocrine syndrome type 1 , which affects the endocrine system, STAT3 mutation, which affects the connective tissues, and immune dysregulation-polyendocrinopathy-enteropathy-X-linked syndrome, which causes chronic diarrhea [15, 16]. Infection may not be the only sign for the clinical and immunological diagnosis of PIDs and, indeed, it may not even be the most useful sign in some PIDs. Furthermore, contrary to the traditional view that PID patients have recurrent, severe infections caused by various pathogens, we have found that some PIDs predispose patients to infection with only one or a few pathogens [17-21].

The J Project program, supported mostly by a special grant from Biotest Hungaria Kft., and the recently launched PID Centers Network program, supported by the New Yorkbased Jeffrey Modell Foundation and Octapharma Nordic, are the two most ambitious PID awareness programs in ECE countries. These programs should harmonize the diagnosis and appropriate treatment of PID patients throughout Europe, by increasing awareness and accelerating the movement towards molecular medicine. The affiliation of the J Project Group to the CEJI will provide us with an excellent opportunity to improve communication and interactions, by publishing our clinical research work and information about the progress of the project. The CEJI should also benefit from the publication of an increasing number of PID-focused papers, given the rapid progress in this field anticipated over the next few years.

\section{References}

1. Pac M, Bustamante J, Buda P, et al. (2012): Disseminated Mycobacterium tuberculosis complex infection in a girl with partial dominant IFN- $\gamma$ receptor 1 deficiency. Centr Eur J Immunol 37: 378-381.

2. Pirrone A, Markelj G, Piscianz E, et al. (2012): Primary immunodeficiency diseases in two neighboring pediatric centers: registry data bring out a wide spectrum of diseases with complex clinical presentations. Centr Eur J Immunol 37: $365-370$. 
3. Al-Muhsen S, Casanova JL (2008): The genetic heterogeneity of mendelian susceptibility to mycobacterial diseases. J Allergy Clin Immunol 122: 1043-1051.

4. Jouanguy E, Altare F, Lamhamedi S, et al. (1996): Interferongamma-receptor deficiency in an infant with fatal bacille Calmette-Guérin infection. N Engl J Med 335: 1956-1961.

5. Newport MJ, Huxley CM, Huston S, et al. (1996): A mutation in the interferon-gamma-receptor gene and susceptibility to mycobacterial infection. N Engl J Med 335: 1941-1949.

6. Dorman SE, Holland SM (1998): Mutation in the signal-transducing chain of the interferon-gamma receptor and susceptibility to mycobacterial infection. J Clin Invest 101: 2364-2369.

7. Chapgier A, Kong XF, Boisson-Dupuis S, et al. (2009): A partial form of recessive STAT1 deficiency in humans. J Clin Invest 119: 1502-1514.

8. Hambleton S, Salem S, Bustamante J, et al. (2011): IRF8 mutations and human dendritic-cell immunodeficiency. N Engl J Med 365: 127-138.

9. Bogunovic D, Byun M, Durfee LA, et al. (2012): Mycobacterial disease and impaired IFN- $\gamma$ immunity in humans with inherited ISG15 deficiency. Science 337: 1684-1688.

10. Sadeghi-Shabestari M, Rezaei N (2009): Disseminated bacille Calmette-Guérin in Iranian children with severe combined immunodeficiency. Int J Infect Dis 13: e420-3.

11. Maródi L, Casanova JL (2009): Primary immunodeficiency diseases: the J Project. Lancet 373: 2179-2181.

12. Maródi L; J Project Study Group (2011): The creation and progress of the J Project in Eastern and Central Europe. Ann N Y Acad Sci 1238: 65-73.

13. Al-Herz W, Bousfiha A, Casanova JL, et al. (2011) Primary immunodeficiency diseases: an update on the classification from the international union of immunological societies expert committee for primary immunodeficiency. Front Immunol 2: 54 .

14. Maródi L, Casanova JL (2009): Novel primary immunodeficiencies relevant to internal medicine: novel phenotypes. J Intern Med 266: 502-506.

15. Maródi L, Cypowyj S, Tóth B, et al. (2012): Molecular mechanisms of mucocutaneous immunity against Candida and Staphylococcus species. J Allergy Clin Immunol 130: 10191027.

16. Barzaghi F, Passerini L, Bacchetta R (2012): Immune dysregulation, polyendocrinopathy, enteropathy, X-linked syndrome: a paradigm of immunodeficiency with autoimmunity. Front Immunol 3: 211.

17. Erdõs M, Uzvölgyi E, Nemes Z, et al. (2005): Characterization of a new disease-causing mutation of SH2D1A in a family with X-linked lymphoproliferative disease. Hum Mutat 25: 506.

18. Casanova JL, Abel L (2007): Primary immunodeficiencies: a field in its infancy. Science 317: 617-619.

19. Ku CL, Picard C, Erdös M, et al. (2007): IRAK4 and NEMO mutations in otherwise healthy children with recurrent invasive pneumococcal disease. J Med Genet 44: 16-23.

20. Alcaïs A, Quintana-Murci L, Thaler DS, et al. (2010): Lifethreatening infectious diseases of childhood: single-gene inborn errors of immunity? Ann N Y Acad Sci 1214: 18-33.

21. Jiao H, Tóth B, Erdos M, et al. (2010): Novel and recurrent STAT3 mutations in hyper-IgE syndrome patients from different ethnic groups. Clin Endocrinol (Oxf) 72: 641-647. 